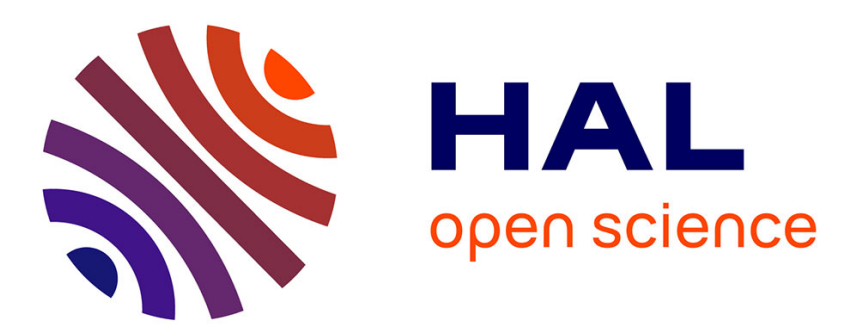

\title{
Modified Mode1 of Initial Magnetic Permeability of Polycrystalline Ferrites
}

G. Rankis, V. Yurshevich, J. Jankovskis

\section{To cite this version:}

G. Rankis, V. Yurshevich, J. Jankovskis. Modified Mode1 of Initial Magnetic Permeability of Polycrystalline Ferrites. Journal de Physique IV Proceedings, 1997, 07 (C1), pp.C1-207-C1-208. 10.1051/jp4:1997178 . jpa-00255125

\section{HAL Id: jpa-00255125 https://hal.science/jpa-00255125}

Submitted on 1 Jan 1997

HAL is a multi-disciplinary open access archive for the deposit and dissemination of scientific research documents, whether they are published or not. The documents may come from teaching and research institutions in France or abroad, or from public or private research centers.
L'archive ouverte pluridisciplinaire HAL, est destinée au dépôt et à la diffusion de documents scientifiques de niveau recherche, publiés ou non, émanant des établissements d'enseignement et de recherche français ou étrangers, des laboratoires publics ou privés. 


\title{
Modified Model of Initial Magnetic Permeability of Polycrystalline Ferrites
}

\author{
G. Rankis, V. Yurshevich and J. Jankovskis \\ Riga Technical University, 12 Azenes str, LV-1048 Riga, Latvia
}

\begin{abstract}
IMP) is offered for a wide class of polycrystalline ferrites (PF): Ni and NiZn ferrites. YIG. Within the scope of this model, IMP and other structure-dependent properties of normally sintered ferrites are explatined by two pinning mechanisms of the displacing flat domain walls (DW). The main mechanism is due to the interacion between DW and the inhomogeneous microstresses in the immediate vicinity of the grain boundaries (GB). The second mechanism occurs dec to the closure domains.
\end{abstract}

\section{INTRODUCTION}

A great body of data is available about IMP and other characteristics of PF. However, until now insufficient attention has been paid to models that are able to explain variety of IMP data, such as: wide range of numerical values, temperature and frequency dependence of IMP. The commonly used Globus's model (bending DW is fixed on GB) gives the temperature dependence of IMP which is sometimes in disagreement with the experiment. It also cannot explain the wide range of $\mathrm{DW}$ resonance frequencies. In this work we consider the materials, in which IMP is determined by DW displacement. The domination of DW displacement over the rotation processes in such materials follows from the results of the investigations of magnetic spectra. In this case IMP depends on two groups of factors: the domain structure (DS) and the hindrances to DW motion (DW pinning mechanisms). The microstructure of PF also plays an important role, and the density of the magnetic poles on GB determines DS. The major hindrances to DW motion are concentrated in the immediate vicinity of GB. The understanding of these factors inftuence on IMP is associated with the properties of PF as sintered materials.

The normal grain growth, determined by the migration of $\mathrm{GB}$, takes place at the last phase of sintering [1]. The crystallite region that remains belind migrating ( $B B$ contains a few defects (has nearly perfect structure). Such a feature of the microstructure of $P F$ determines the first property of the hindrances to DW motion: they are located near the GB.

For the interpretation of IMP as a structure dependent parameter, it is important to take into account the role of the structural length scales of the material. Together with the grain size, some other scales, which are sufficient for the nucrostructure and magnetic structure. may be determined. The smallest of them is the crystal lattice parameter. Other characteristic length is determined by the structure of GB which consists of the regions of better and worst coincidence [2]; their sizes $\Delta \mathrm{r}$ are $5 \ldots 10$

$\mathrm{nm}$ [3]. The magnetic nature length scale - parameter of DW width $\delta=\left(A /\left|K_{1}\right|\right)^{0.5}$, where A - exchange constant, $K_{1}-$ crystallographic anisotropy constant, is sufficient for DS and for the pinning forces. For materials mentioned here $\delta \approx 0,15 \ldots 0,4$ $\mu \mathrm{m}$ [4]. All considered scales give the hierarchy of the characteristic lengths for PF : lattice parameter - Inm, size of the region of better and worst coincidence on GB- $10 \mathrm{~nm}$. DW width - $0,1 \mu \mathrm{m}$, grain size - $1 \ldots 10 \mu \mathrm{m}$.

There are inner microstresses in all PF. Universal mechanism of these stresses in PF has been proposed by Pascard and Globus [5]. They are determined by the disorientation of the crystal lattices of the neighbouring grains and by volume and linear mag.netostriction. The manifestation of the stresses is the total anisotropy $K$ [5]. Here we consider the ferrites with IMP values from several tens to several thousands. They have some common properties: approximately identical anion lattices and GB structures, approximately equal microstructure parameters, values of $\delta$, that differ not more than 3 times.

\section{THE PINNING MECHANISMS FOR DOMAIN WALL}

In [7] the main pinning mechanism of $D W$ has been proposed: interaction of DW with the microstresses in the vicinity of GB. The stresses described in [5] were considered as almost constant in the volume of the grain. The proposed inodel is based on the assumption that they have a component that varies with the spatial coordinates along GB. The microstresses origin is due to the disorientation of the magnetic axes of the grains, and their sources are located on GB. As a result of the alternation 
of the regions with best and worst coincidence on $\mathrm{GB}$, the magnetostrictional deformation creates the inhomogeneous stresses along GB. Thus DW is linked near GB with the regions of the increased anisotropy $\Delta K \approx\left(|K|-\left|K_{1}\right|\right)$. The spatial period and their sizes is $\Delta r$. The location of DW will be determined by the condition, that DW near GB contains the minimal number of regions with increased anisotropy. This model of the hindrances is related with Neel's model of non-magnetic inclusions with sizes less than DW width [6]. For a material with single DW in the grain (Fig. 1.a) our model gives

$$
\mu_{a}-1 \approx A|K|\left(\lambda_{100} / \lambda_{111}\right) D_{a} /\left|K_{1}\right|\left(|K|-\left|K_{1}\right|\right)
$$

where $\lambda_{100}, \lambda_{11}$ - magnetostriction constants, $D a$ - mean grain diameter. This model gives satisfactory coincidence with the

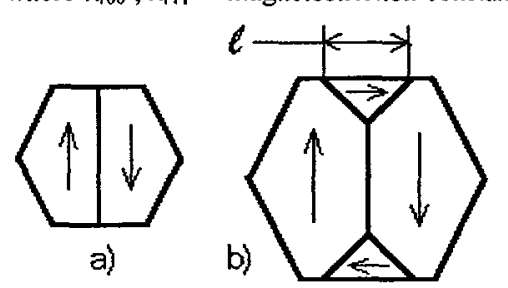

Figure 1: DS in PF grains experiment [7] for IMP temperature dependences of Ni ferrite and YIG sintered by Globus's method [8]. The function $\mu_{a}\left(D_{a}\right)$ for ferrites manufactured by traditional technology is more complicated [9]. The rate of the IMP change decreases above grain sizes $2 . . .3 \mu \mathrm{m}$. This bend cannot be explained by the assumption that there are two $180^{\circ} \mathrm{DW}$ in the grain. If the pinning mechanism not changes by the appearance of the next DW, the IMP must increase.

If we assume that in materials with $D a>2 \mu \mathrm{m}$ may be DS with closure domains (CD) (Fig.l.b), the second pinning mechanism is possible: external force displacing $\mathrm{CD}$ with non- $180^{\circ} \mathrm{DW}$ creates the elastic deformations that oppose to the displace of $C D$ and the linked strained region. If this is the only pinning mechanism, then IMP is [10]:

$$
\mu_{a}-1 \approx(32 \pi / 3) M_{s}^{2} D_{a} / C_{11} \lambda_{111}^{2} l
$$

where $M s$ - saturation magnetization, $C_{11}$ - elastic modulus, $l$ - size of $\mathrm{CD}$. It must be noted that the two pinning mechanisms have different temperature dependences: equ.(1) gives IMP increases with temperature, equ.(2) - the one that decreases. If the both pinning mechanisms take place, IMP follows from the relation $\mu_{a}-1 \approx M_{s}^{2} /\left(a_{1} \alpha_{1}+a_{2} \alpha_{2}\right)$ where $\alpha_{1}, \alpha_{2}-$ quasielastic coefficients of DW; $a_{1}, a_{2}$ - weight factors. For some materials [11] various temperature dependences of IMP (including the weak dependence) over a wide range of their change may be interpreted by the variety of the weight factors.

DS with CD allows a unified interpretation of many additional effects in PF. The bend on the curve $\mu_{a}\left(D_{a}\right)$ and the variety of IMP temperature dependences have been noted here. The other results are: temperature changes on the magnetic spectra of $\mathrm{NiZn} \mathrm{[12]} \mathrm{and} \mathrm{MnZn} \mathrm{[13]} \mathrm{ferrites,} \mathrm{the} \mathrm{change} \mathrm{of} \mathrm{the} \mathrm{intensity} \mathrm{of} \mathrm{the} \Delta E$-effect in a ferrite after the additional annealing [14] and others [10]. The model of the acoustic emission mechanism in PF has been formulated in [10]. It is found on the assumption of $C D$ existence and is able to explain the sufficient properties of this effect. The essential arguments in favour of this hypothesis are the results of experimental investigations of the $\Delta \mathrm{E}$-effect dependence on the magnetization in NiZn ferrite [14], where DW displacement and magnetization rotation processes are separated. The component of $\Delta E$-effect due to DW displacement increased after the additional heat treatment, which gives the consequent grain growth. Then the assumption that $\mathrm{CD}$ exists explains the increasing intensity of the $\Delta \mathrm{E}$-effect.

The DW pinning mechanism proposed here can be attributed also to the $\mathrm{MnZn}$ ferrites with $\mathrm{Da}$ values greater than some $\mu \mathrm{m}$. Conclusions. The main features of the proposed model for IMP: a displacing flat DW is held in a defective layer near the GB by small regions of internal microstresses (main pinning mechanism) and by stresses in the area of $C D$.

\section{References}

[1] Kurtz S.K., Carpay F.M.A. J.Appl.Phys.51 (1980) 5725-5754

[2] Gleiter H. Mater. Sci. Eng. 52 (1982) 91-131

[3] Nakata A., Chihara H., Sasaki A. J.Appl.Phys. 57 (1985) 4177-4179

[4] Rankis G. Dynamics of magnetization in polycrystalline ferrites (Zinatne, Riga, 1981) p. 28-32 (in Russian)

[5] Pascard H., Globus A. Phys.Rev.B. 24 (1981) 6610-6619

[6] Neel L. Cahiers de phys. N.25 (1944) 21

[7] Rankis G. Bull.Latv.Acad.Sci.,Phys.Techn.Sc. N.2 (1984) 27-42 (in Russian)

[8] Globus A. J.Phys.(France) 38 (1977) 1-15

[9] Gieraltowski J. "Interdependence between the grain size and the wall dimension in magnetically soft ferrites", Ferrites, Proc. Internat. Conf., Japan, Sept.-Oct. 1980, pp. 277-280

[10] Rankis G., Jankovskis J., Yurshevich V. "Model of the mechanism of acoustic emission in polycrystalline ferrites", Noise in Physical Systems and I/f fluctuations, Proc. 13th Internat. Conf., Palanga, Lithuania, 29 May- 3 June 1995,V. Bareikis, R.Katilius Eds. (World Scientific, Singapore, New Jersey,..., 1995) pp. 729-732

[11] Globus A., Monjaras V. IEEE Trans. MAG-11 (1975) 1300-1302

[12] Rankis G., Yurshevich V., Brivkalns K. Bull.Latv.Acad.Sci.,Phys.Techn.Sc. N5 (1986) 38-45 (in Russian)

[13] Yurshevich V., Rankis G. Bull.Latv.Acad.Sci.,Phys.Techn.Sc. N.1 (1987) $63-69$ (in Russian)

[14] Terstegge H. Ztschr.Angew.Phys. 30 (1970) 103-109 